\title{
Branching Reactions in Polycarbonate: A Density Functional Study
}

\author{
J . Akola and R. O. J ones* \\ Institut für Festkörperforschung, Forschungszentrum J ülich, D-52425 J ülich, Germany \\ Received October 28, 2002; Revised Manuscript Received December 16, 2002
}

\begin{abstract}
Branching can have a dramatic effect on the properties of polymers, and bisphenol A polycarbonate (BPA-PC) is no exception. We describe here the results of a density functional (DF) study of branching that can occur during transesterification reactions in BPA-PC in the presence of catalysts. We find that sodium phenoxide ( $\mathrm{NaOPh}$ ) can lead to different branched products, because the $\mathrm{Na}$ ion can bond to different $\mathrm{O}$ atoms simultaneously. Tetraphenyl phosphonium phenoxide, which can be used as an alternative catalyst to NaOPh in BPA-PC synthesis, does not lead to branching, because steric hindrance prevents its active sites from approaching the $\mathrm{O}$ atoms.
\end{abstract}

\section{Introduction}

Polymers formed by the stepwise addition of difunctional units have a one-dimensional topology, examples being polyethylene (PE), polystyrene (PS), and poly(vinyl chloride) (PVC). The topology changes induced by the presence of multifunctional units can result in systems such as branched chains, stars, and cross-linked networks with dramatically different glass and melting transition temperatures, morphologies, size distributions, viscosities, and other properties. ${ }^{1}$ Branching may also result in new phases such as gels and rubbers, where the entire system may be viewed as a single cross-linked molecule. ${ }^{2}$

Polycarbonates $(\mathrm{PC})$ are thermoplastic materials with excellent transparency and high impact resistance, and their many applications include optical instruments, el ectronic appliances, and automobile parts. They can be prepared by the reaction of an aromatic dihydroxy compound [e.g., bisphenol A (BPA)] with a carbonate precursor such as phosgene (interfacial polycondensation) or in a melt by transesterification of BPA with diphenyl carbonate (DPC) (melt method, MM). The latter avoids the use of phosgene and chlorinated solvents and has environmental advantages, but branching, cross-linking, and other side reactions caused by temperatures of $200-300^{\circ} \mathrm{C}$ can lead to discolored or degraded products. The carboxylic branching structure observed in reactive pyrolysis in MM-PC production ${ }^{3}$ indicated that the PC chain is most susceptible to branching at the carbonate group, where transesterification occurs in PC synthesis. ${ }^{4-6}$

In some cases branching is desired, because longchain branched PC modifications show special shear viscosity behavior that makes them suitable for blow molding applications. The degree of branching can be controlled by branching agents such as THPE $[1,1,1-$ tris(p-hydroxyphenol)ethane $]^{7}$ and polyphenols. ${ }^{8-10}$ Krabbenhoft and Boden, ${ }^{9}$ for example, reported the production of branched polycarbonates with high shear sensitivity using the ring-opening polymerization (ROP) of cyclic oligomers of BPA carbonates with tri- and tetraphenol reagents.

In recent years, our group has performed numerous theoretical studies of ROP reactions in the BPA-PC melt, including density functional (DF) calculations on

\footnotetext{
* Corresponding author. E-mail: r.jones@fz-juelich.de.
}

the role of different catalysts and additives in PC synthesis.5,6,11 We have also developed a simplified model of ROP in BPA-PC melts ${ }^{12}$ that has been extended to include a varying number of active (cataIytic) sites, ${ }^{13}$ and multifunctional units. ${ }^{14}$ The multifunctional units lead to branching and, under certain conditions, to gel formation. This work is extended here to a DF study of a two-step branching reaction in BPA$P C$. The first stage involves the reaction between phenyl 5-tert-butyl-2 sodiumoxybenzoate (PBNaOB) and DPC (Figure $1 b$ ). The former is a branching initiator in a polycarbonate melt formed from DPC + (one-sided-tertbutyl terminated DPC) by a Fries rearrangement reacti on catalyzed by sodium phenoxide (NaOPh). The most stable form of PBNaOB (Figure 1a) underscores the ability of $\mathrm{Na}$ to form "hypervalent" bonds with more than one $\mathrm{O}$ atom. The products of this first step are $\mathrm{NaOPh}$ (Figure 1d) and the "branched" carbonate (Figure $1 \mathrm{C}$ ), and the second stage examines how the reaction of these two molecules can lead to a different branched product. The labeling of the atoms is shown in Scheme 1.

We focus on the transesterification pathway ${ }^{3}$ and the role of the catalyst $\mathrm{NaOPh}$. We find that the $\mathrm{Na}$ can interact with several oxygen atoms simultaneously, and branching is enhanced by the proximity of the active sites for transesterification. In practice, the choice of catalyst and melt temperature is crucial for the implementation of the melt method, 4,15,16 and we compare $\mathrm{NaOPh}$ with tetraphenyl phosphonium phenoxide $\left(\mathrm{PPh}_{4-}\right.$ $\mathrm{OPh})$, for which steric hindrance prevents branching. Our earlier studies have shown that both $\mathrm{NaOPh}$ (and $\mathrm{LiOPh}$ ) activate the ROP of BPA-PC, ${ }^{5}$ and $\mathrm{NaOPh}$ and $\mathrm{PPh}_{4} \mathrm{OPh}$ catalyze chain growth in $\mathrm{PC} .{ }^{6}$ Their industrial use is well documented. ${ }^{17-20}$

In section II, we give necessary details of the calculations, and in section III, we present the results for a sequence of reactions involving $\mathrm{NaOPh}$ and calculations for $\mathrm{PPh}_{4} \mathrm{OPh}$. Our concluding remarks are given in section IV.

\section{Method of Calculation}

The method of calculation has been described in detail previously. ${ }^{21}$ The electron-ion interaction is represented by ionic pseudopotentials with the (nonlocal) form suggested by Troullier and Martins. ${ }^{22}$ We use periodic boundary conditions and an orthorhombic unit cell with 
Scheme 1. Labeling of Atoms in (a) DPC + , (b) PBNaOB, and (c) Sodium Phenoxide<smiles>CC(C)(C)c1ccc(OC(=O)Oc2ccccc2)cc1</smiles>

(a)<smiles>CC(C)(C)C1C2CC3C(ONOC31)C2Oc1ccccc1</smiles>

(b)<smiles>[AlH2]O[14c]1[14cH][14cH][14cH][14cH][14cH]1</smiles>

(c)

lattice constants chosen to ensure that the images of the reacting systems are well-separated. The orbitals are expanded in terms of a plane wave basis (kinetic energy cutoff of $35 \mathrm{au})$ using a single point $(\mathbf{k}=0)$ in the Brillouin zone. This basis has been shown to provide a reliable description of energy differences in these systems, and we use the approximation of Perdew, Burke, and Ernzerhof (PBE) ${ }^{23}$ for the exchange-correlation energy. Vibration frequencies are calculated using linear response theory.

As in our earlier simulations, we have studied the energy surfaces by varying a reaction coordinate $R_{C}$, such as the distance between the $C$ atom of a carbonate group and an $\mathrm{O}$ atom on a phenoxyl group, until a structural transformation or a large energy change takes place. For large values of $R_{C}$ (typically $>5 \AA$ ), the weak interaction between the reactants allows changes of $1 \AA$, but progressively shorter steps $(0.5-0.1 \AA)$ become necessary as the reaction proceeds. For each value of $R_{C}$, we relax all other degrees of freedom of the structure using molecular dynamics, ${ }^{24}$ until the energy gradients along the unconstrained directions are less than an appropriate tolerance. A single reaction coordinate is not sufficient to describe most reactions, and others are adopted as necessary. There is no guarantee, of course, that this-or any other-method can determine the optimum reaction path, but the present calculations have been very extensive. Structures corresponding to minima in the energy surface are generally relaxed, i.e., the constraint on $\mathrm{R}_{\mathrm{C}}$ is removed.

\section{Branching Reactions of Polycarbonate}

A. Structures and Properties of Reactants. The reactants are shown in Figure 1, and the structural parameters, effective charges (ESP charges calculated from a fit to the electrostatic potential), di pole moments, and characteristic vibration frequencies are given in Table 1. In both $\mathrm{NaOPh}$ and $\mathrm{PBNaOB}$ an unsaturated oxygen atom $\left(\mathrm{O}_{1}\right)$ interacts with $\mathrm{Na}$, and $\mathrm{PBNaOB}$ has an additional $\mathrm{Na}-\mathrm{O}$ interaction of comparable strength with the carbonyl oxygen $\left(\mathrm{O}_{2}\right)$ (see Table 1 ). The large dipole moment results from the charge transfer from

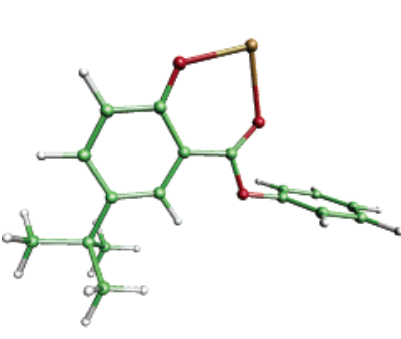

(a)

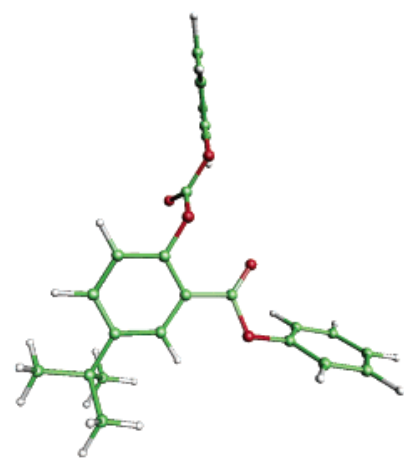

(c)

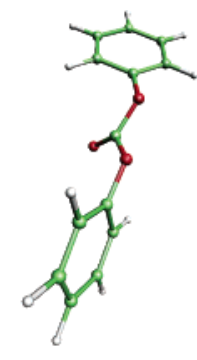

(b)

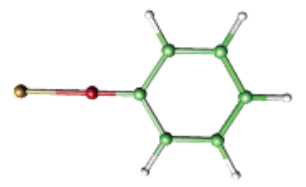

(d)
Figure 1. Structures of (a) PBNaOB, (b) DPC, (c) branched PC ortho ester, and (d) sodium phenoxide. Key: C, green; O, red; $\mathrm{H}$, white; $\mathrm{Na}$, brown.

$\mathrm{Na}$ to the oxygen and other atoms, and the increased $\mathrm{Na}-\mathrm{O}$ coordination makes the individual $\mathrm{Na}-\mathrm{O}$ contacts weaker than in NaOPh. The dihedral angles around the ester group differ markedly from those in $\mathrm{DPC}+$ due to the $\mathrm{C}-\mathrm{C}$ ester linkage. PBNaOB has a mirror plane with the peripheral phenyl group rotated by $90^{\circ}$ from the plane of the other phenyl group.

The calculated vibrational densities of states of DPC+ and $\mathrm{PBNaOB}$ are similar, but the presence of $\mathrm{Na}$ and the related charge transfer (see Table 1) causes a red shift of over $100 \mathrm{~cm}^{-1}$ in the $\mathrm{C}-\mathrm{O}$ double bond stretch. A strong peak near $360 \mathrm{~cm}^{-1}$ in PBNaOB is absent for $D P C+$, and analysis of the vibrational eigenvectors shows that this mode involves bending of the $\mathrm{O}-\mathrm{Na}-\mathrm{O}$ contact coupled with "breathing" of the phenoxyl and ester groups. The small blue shift in the lowest two of the three $\mathrm{C}-\mathrm{H}$ stretching peaks is related to $\mathrm{Na}$-induced charge transfer from the terminal butyl-group in PB$\mathrm{NaOB}$.

B. Reactions involving NaOPh. Transesterification caused by the nucleophilic attack of PBNaOB on DPC is similar to the reaction observed in $P C$ synthesis between a chain-terminating phenoxide group $(\mathrm{NaOPh}$. ..) and DPC. The initial reaction coordinate ( $\mathrm{R}$ in Table 2 ) is the distance between the carbonate carbon in DPC and the phenoxyl oxygen $\left(\mathrm{O}_{1}\right)$ in PBNaOB. The structural changes during the reactions are shown in Figures 2 and 3 , and the corresponding changes in total energy for all reaction coordinates ( $R, S, T, D, U$, see below) are shown in Figure 4 and Table 2.

The starting configuration consists of $\mathrm{PBNaOB}$ and DPC molecules at $R=8.0 \AA$, where the interaction between molecules is negligible and the energy is defined to be zero. Changes in $R$, initially $1 \AA$, were reduced as the reaction proceeded. The total energy of the system decreases at first due to the attraction between the $\mathrm{Na}$ cation and carbonyl oxygen, leading to 
Table 1. Results of DF Calculations for Molecules in Figure 1: Bond Lengths in angstroms, Bond and Dihedral Angles in degrees, Atomic Charges (e), Dipole Moments (debye) and Vibration Frequencies $\left(\mathrm{cm}^{-1}\right)^{\mathrm{a}}$

\begin{tabular}{|c|c|c|c|}
\hline atoms & DPC+ & PBNaOB & $\mathrm{NaOPh}$ \\
\hline $\begin{array}{l}\mathrm{C}_{7}-\mathrm{O}_{1} \\
\mathrm{C}_{7}-\mathrm{O}_{2} \\
\mathrm{C}_{7}-\mathrm{O}_{3} \\
\mathrm{C}_{4}-\mathrm{O}_{1} \\
\mathrm{C}_{8}-\mathrm{O}_{3} \\
\mathrm{C}_{7}-\mathrm{C}_{5} \\
\mathrm{Na}-\mathrm{O}_{1} \\
\mathrm{Na}-\mathrm{O}_{2}\end{array}$ & $\begin{array}{l}1.36 \\
1.21 \\
1.37 \\
1.41 \\
1.41 \\
(2.98, \text { b } 3.56)\end{array}$ & $\begin{array}{l}(3.01) \\
1.24 \\
1.41 \\
1.29 \\
1.40 \\
1.45 \\
2.24 \\
2.35\end{array}$ & $\begin{array}{l}1.32 \\
2.11\end{array}$ \\
\hline $\begin{array}{l}\mathrm{O}_{1}-\mathrm{C}_{7}-\mathrm{O}_{2} \\
\mathrm{O}_{1}-\mathrm{C}_{7}-\mathrm{O}_{3} \\
\mathrm{O}_{2}-\mathrm{C}_{7}-\mathrm{O}_{3} \\
\mathrm{C}_{4}-\mathrm{O}_{1}-\mathrm{C}_{7} \\
\mathrm{C}_{7}-\mathrm{O}_{3}-\mathrm{C}_{8} \\
\mathrm{C}_{5}-\mathrm{C}_{7}-\mathrm{O}_{2} \\
\mathrm{C}_{5}-\mathrm{C}_{7}-\mathrm{O}_{3} \\
\mathrm{C}_{4}-\mathrm{O}_{1}-\mathrm{Na} \\
\mathrm{C}_{7}-\mathrm{O}_{2}-\mathrm{Na} \\
\mathrm{O}_{1}-\mathrm{Na}-\mathrm{O}_{2}\end{array}$ & $\begin{array}{l}128.0 \\
104.7 \\
127.3 \\
120.1 \\
118.3\end{array}$ & $\begin{array}{l}117.4 \\
116.1 \\
129.9 \\
112.8 \\
132.9 \\
128.5 \\
80.1\end{array}$ & 180.0 \\
\hline $\begin{array}{l}\mathrm{C}_{3}-\mathrm{C}_{4}-\mathrm{O}_{1}-\mathrm{C}_{7} \\
\mathrm{C}_{4}-\mathrm{O}_{1}-\mathrm{C}_{7}-\mathrm{O}_{2} \\
\mathrm{O}_{2}-\mathrm{C}_{7}-\mathrm{O}_{3}-\mathrm{C}_{8} \\
\mathrm{C}_{7}-\mathrm{O}_{3}-\mathrm{C}_{8}-\mathrm{C}_{9} \\
\mathrm{C}_{4}-\mathrm{C}_{5}-\mathrm{C}_{7}-\mathrm{O}_{2}\end{array}$ & $\begin{array}{l}40.2 \\
10.2 \\
4.3 \\
56.5\end{array}$ & $\begin{array}{l}0.0 \\
90.0 \\
0.0\end{array}$ & \\
\hline $\begin{array}{l}\mathrm{Q}\left(\mathrm{C}_{7}\right) \\
\mathrm{Q}\left(\mathrm{O}_{1}\right) \\
\mathrm{Q}\left(\mathrm{O}_{2}\right) \\
\mathrm{Q}\left(\mathrm{O}_{3}\right) \\
\mathrm{Q}\left(\mathrm{C}_{4}\right) \\
\mathrm{Q}\left(\mathrm{C}_{5}\right) \\
\mathrm{Q}\left(\mathrm{C}_{8}\right) \\
\mathrm{Q}(\mathrm{Na})\end{array}$ & $\begin{array}{l}0.88 \\
-0.41 \\
-0.55 \\
-0.43 \\
0.38 \\
-0.25 \\
0.37\end{array}$ & $\begin{array}{l}0.95 \\
-0.87 \\
-0.75 \\
-0.53 \\
0.72 \\
-0.64 \\
0.53 \\
0.89\end{array}$ & $\begin{array}{l}-1.15 \\
0.84 \\
-0.38 \\
0.93\end{array}$ \\
\hline dipole & 0.7 & 7.9 & 12.1 \\
\hline $\begin{array}{l}\mathrm{C}_{7}-\mathrm{O}_{2} \text { stretch } \\
\mathrm{C}_{7}-\mathrm{O}_{1,3} \text { stretch } \\
\mathrm{C}_{8}-\mathrm{O}_{3} \text { stretch } \\
\mathrm{C}_{7}-\mathrm{C}_{5} \text { stretch } \\
\mathrm{C}_{4}-\mathrm{O}_{1} \text { stretch } \\
\mathrm{Na}-\mathrm{O} \text { stretch }\end{array}$ & $\begin{array}{l}1760 \\
1130-1160 \\
1160-1210^{c}\end{array}$ & $\begin{array}{l}1660 \\
1130 \\
1190 \\
1310 \\
1480 \\
490-510\end{array}$ & $\begin{array}{l}1480 \\
570\end{array}$ \\
\hline
\end{tabular}

a The values in parentheses do not involve chemical bonding. ${ }^{b} \mathrm{~F}$ or symmetry reasons, we give the $\mathrm{C}_{7}-\mathrm{C}_{3}$ distance. ${ }^{\mathrm{C}}$ Includes also $\mathrm{C}_{4}-\mathrm{O}_{1}$ stretching.

a minimum of $-13.4 \mathrm{kcal} / \mathrm{mol}$ at $3.5 \AA$ for a structure where $\mathrm{Na}$ has bonds between 2.3 and $2.5 \AA$ with three $\mathrm{O}$ atoms $\left(\mathrm{O}_{1}, \mathrm{O}_{2}\right.$ and $\mathrm{O}_{c}$, the carbonyl $\mathrm{O}$ of $\left.\mathrm{DPC}\right)$. Constraint-free optimization leads to an energy of -14.6 $\mathrm{kcal} / \mathrm{mol}$ for $\mathrm{R}=3.80 \AA$ (see Table 1 ), which is a measure of the strength of the pairwise interaction between $\mathrm{Na}$ and $\mathrm{O}_{c}$. F urther reduction of $\mathrm{R}$ leads to steric hindrance and a rapid increase in energy. For $\mathrm{R}<2.0$, the total energy of the system is positive, and the DPC carbonate group distorts from its planar $\mathrm{sp}^{2}$ configuration. The phenoxyl $\mathrm{O}\left(\mathrm{O}_{1}\right)$ gradually loses its $\mathrm{Na}$ contact, and the single bond formed with the carbonate $\mathrm{C}$ leads to a tetrahedral $\mathrm{sp}^{3}$ configuration at $\mathrm{R}=1.5 \AA$.

Reduction of $\mathrm{R}$ to $1.3 \AA$ does not favor the reaction, because interactions with $\mathrm{O}_{1}$ and $\mathrm{O}_{2}$ restrict the motion of $\mathrm{Na}$ and prohibit the formation of new $\mathrm{Na}-\mathrm{O}$ bonds. We have stretched one of the carbonate $\mathrm{C}-\mathrm{O}$ single bonds and applied constraints to the $\mathrm{Na}-\mathrm{O}$ distance and dihedral angles involving $\mathrm{Na}$. Only the first of these (S in Table 1) led to a small increase in the total energy to a maximum (at a C -0 separation of $1.9 \AA$ ) of $7.98 \mathrm{kcal} /$ $\mathrm{mol}$, over $20 \mathrm{kcal} / \mathrm{mol}$ higher than the previous minimum. We expect (see below) that this maximum could be made smoother by combining the stretch $\mathrm{S}$ with a displacement of $\mathrm{Na}$. Increasing the $\mathrm{C}-\mathrm{O}$ separation leads to a planar $\left(\mathrm{sp}^{2}\right)$ carbonate group, while Na retains its two oxygen contacts. The phenoxyl radical formed moves until $\mathrm{Na}$ is above the phenoxyl ring, and the energy has a local minimum $(+2.79 \mathrm{kcal} / \mathrm{mol})$ for $\mathrm{S}=$ $2.6 \AA$ (relaxation yields $+2.53 \mathrm{kcal} / \mathrm{mol}$ for $\mathrm{S}=2.74 \AA$; see Table 2).

The interaction between the phenoxyl radical and $\mathrm{Na}$ is increased when the former is removed from the branched product by applying the same constraint (S). This leads to a minimum in the total energy $(-1.69 \mathrm{kcal} /$ mol for $\mathrm{S}=3.97 \AA$ ) when the system is relaxed (from $3.2 \AA$ ) without constraints. The result is a branched molecule with three aromatic groups linked to carbonate and ester groups, together with $\mathrm{NaOPh}$ where $\mathrm{Na}$ forms three $\mathrm{Na}-\mathrm{O}$ bonds (with lengths 2.29, 2.54, and 2.65 $\AA$ ) and one low-energy hydrogen bond between phenoxyl oxygen $\mathrm{O}_{\mathrm{p}}$ and an aromatic $\mathrm{H}$. The difference of over 10 $\mathrm{kcal} / \mathrm{mol}$ between the energy minima arises both from steric hindrance $(\mathrm{O}-\mathrm{O}$ repulsion, dihedral angles) and the weakened $\mathrm{Na}-\mathrm{O}$ bonds.

The branched PC ester with three phenyl groups (F igure $1 c$ ) is obtained by performing separate cal culations on the products of the previous reaction, PC ester and $\mathrm{NaOPh}$. The absence of the oxygen-binding $\mathrm{Na}$ during optimization means that $\mathrm{O}-\mathrm{O}$ repulsion moves the carbonyl O's of the carbonate and ester groups apart, leading to a tilt of the carbonate group and changes in the orientation of the peripheral phenyl group. The energy difference between the reactants and end products (separated "PC ortho ester" and NaOPh) is 25.2 $\mathrm{kcal} / \mathrm{mol}$. The product molecules have one fewer $\mathrm{Na}-\mathrm{O}$ bond (over $10 \mathrm{kcal} / \mathrm{mol}$ ), and the repulsion between the carbonyl O's of the ester and carbonate groups changes some dihedral angles. The energy difference is even larger if Na remains bound to the "PC ortho ester", with formation of a radical or ionic phenoxyl. This differs from our earlier ring-opening polymerization study, ${ }^{5}$ where the number and nature of the bonds in reactants and product were identical and there was a small energy difference.

The vibrational density of states of the PC ortho ester are very similar to those of DPC + . There is a splitting of ester and carbonate $\mathrm{C}-\mathrm{O}$ double bond stretching around $1750-1800 \mathrm{~cm}^{-1}$, and a blue shift of $\mathrm{C}-\mathrm{H}$ stretch modes is related to the charge removal from the butyl group (the molecule has a dipole moment of 4.6 D). The "breathing" of the ester and nearby aryl groups is reduced to $300 \mathrm{~cm}^{-1}$ without $\mathrm{Na}$.

The stability of the ester group against transesterification at the defect site of a PC chain has been studied by reducing the separation between an $\mathrm{NaOPh}$ molecule and the ester group of the branched PC ester. These molecules are the products of the previous reaction, and the simulation was started from the corresponding local energy minimum. The new reaction coordinate ( $T$; see Table 2 and Figure 4) is the distance between the $O_{p}$ and ester $\mathrm{C}$. The starting configuration corresponded to $\mathrm{T}=4.25 \AA$, and initial changes in $\mathrm{T}$ were $0.5 \AA$.

Reducing the separation of the molecules leads to a slower rise in total energy than in the first reaction, indicating greater flexibility in the system. At $2.4 \AA$ $(+1.19 \mathrm{kcal} / \mathrm{mol})$, the energy rises more rapidly, and the increased interaction between the $\mathrm{O}_{p}$ and ester $\mathrm{C}$ causes the ester group to distort from planarity $\left(\mathrm{sp}^{2}\right)$. The reduction of $\mathrm{T}$ to $1.6 \AA(+10.2 \mathrm{kcal} / \mathrm{mol})$ leads to a 
Table 2. Branching Reaction Energetics of BPA-PC: Reaction Coordinates ( $\AA$, for Labels See Text) and Total Energies ( $\mathrm{kcal} / \mathrm{mol})$

\begin{tabular}{|c|c|c|c|c|c|}
\hline step & $\begin{array}{l}\text { reaction } \\
\text { coordinate }\end{array}$ & energy & step & $\begin{array}{l}\text { reaction } \\
\text { coordinate }\end{array}$ & energy \\
\hline $\begin{array}{r}1 \\
2 \\
3 \\
4 \\
5 \\
6 \\
7 \\
8 \\
9 \\
10 \\
11 \\
12 \\
13 \\
14 \\
15 \\
16 \\
17 \\
18\end{array}$ & $\begin{array}{l}R=8.0 \\
R=7.0 \\
R=6.0 \\
R=5.0 \\
R=4.0 \\
R=3.5\left(3.80^{a}\right) \\
R=3.0 \\
R=2.5 \\
R=2.2 \\
R=1.9 \\
R=1.6 \\
R=1.5 \\
R=1.5 \text { and } S=1.7 \\
S=1.9 \\
S=2.2 \\
S=2.6\left(2.74^{a}\right) \\
S=3.2 \\
\text { relaxed }(S=3.97 a)\end{array}$ & $\begin{array}{l}0.00 \\
-0.39 \\
-1.26 \\
-3.77 \\
-11.2 \\
-13.4\left(-14.6^{\mathrm{a}}\right) \\
-12.4 \\
-8.11 \\
-3.83 \\
+2.47 \\
+3.75 \\
+4.45 \\
+5.30 \\
+7.98 \\
+4.47 \\
+2.79\left(+2.53^{\mathrm{a}}\right) \\
-0.54 \\
-1.69 \mathrm{a}\end{array}$ & $\begin{array}{l}18 \\
19 \\
20 \\
21 \\
22 \\
23 \\
24 \\
25 \\
26 \\
27 \\
28 \\
29 \\
30 \\
31 \\
32 \\
33 \\
34 \\
35 \\
36\end{array}$ & $\begin{array}{l}\text { relaxed }(\mathrm{T}=4.25) \\
\mathrm{T}=3.75 \\
\mathrm{~T}=3.25 \\
\mathrm{~T}=2.75 \\
\mathrm{~T}=2.4 \\
\mathrm{~T}=2.1 \\
\mathrm{~T}=1.8 \\
\mathrm{~T}=1.6 \\
\mathrm{~T}=1.6 \text { and } \mathrm{D}_{1} \mathrm{~b} \\
\mathrm{~T}=1.6 \text { and } \mathrm{D}_{2}^{\mathrm{b}} \\
\mathrm{T}=1.5 \text { and } \mathrm{D}_{2}{ }^{\mathrm{b}} \\
\mathrm{U}=1.8 \\
\mathrm{U}=2.1 \\
\mathrm{U}=2.5 \\
\mathrm{U}=3.0\left(\mathrm{U}=3.50^{\mathrm{a}}\right) \\
\mathrm{U}=3.5 \\
\mathrm{U}=4.0 \\
\mathrm{U}=4.5 \\
\text { relaxed }\left(\mathrm{U}=4.17^{\mathrm{a}}\right)\end{array}$ & $\begin{array}{l}-1.69 \\
-1.25 \\
-0.60 \\
+0.22 \\
+1.19 \\
+4.00 \\
+7.96 \\
+10.2 \\
+12.7 \\
+16.0 \\
+17.0 \\
+16.6 \\
+15.6 \\
+11.9 \\
+9.00\left(8.07^{\mathrm{a}}\right) \\
+9.82 \\
+10.3 \\
+9.66 \\
+9.09 \mathrm{a}\end{array}$ \\
\hline
\end{tabular}

${ }^{a}$ Local minimum obtained by removing the most recent contraint. ${ }^{b}$ Dihedral angle changes are $25^{\circ}$ each.

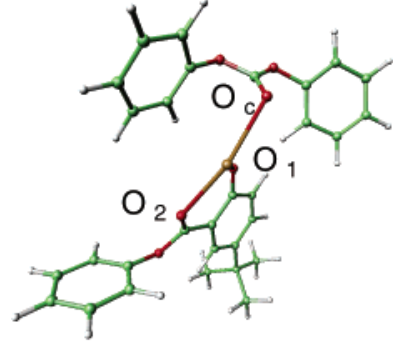

(a)

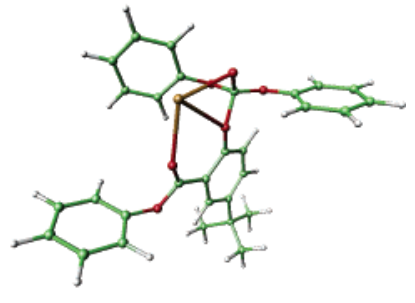

(b)

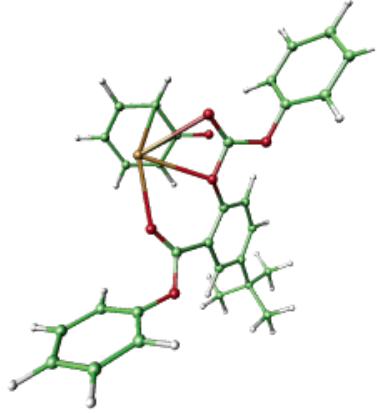

(c)

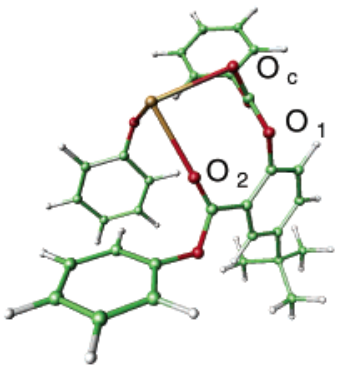

(d)
Figure 2. First reaction stage. The corresponding energies are denoted $2(\mathrm{a}-\mathrm{d})$ in Figure $4 . \mathrm{O}_{\mathrm{c}}$ denotes the carbonyl oxygen of DPC.

tetrahedral $\left(\mathrm{sp}^{3}\right)$ configuration, in analogy to the carbonate group in the previous reaction.

The energy increase of $12 \mathrm{kcal} / \mathrm{mol}$ over the starting configuration arises from changes in $\mathrm{Na}-\mathrm{O}$ bonds (especially in the initial $\mathrm{Na}-\mathrm{O}$ bond of $\mathrm{NaOPh}$ ) and the energy barrier between the $\mathrm{sp}^{2}$ and $\mathrm{sp}^{3}$ configurations of the ester group. Changing the length of the $\mathrm{C}-\mathrm{O}$ bond connecting the ester group with the peripheral phenyl group does not cause it to break, since the $\mathrm{Na}-\mathrm{O}$ interaction prevents the $\mathrm{Na}$ from approaching this $\mathrm{C}-\mathrm{O}$ bond. We have chosen a dihedral angle constraint (involving $\mathrm{Na}$ and atoms from the ester group, denoted by $D_{1}$ in Table 2 and Figure 4) together with the reaction coordinate T. The second displacement of $\mathrm{Na}\left(\mathrm{D}_{2}\right)$ results

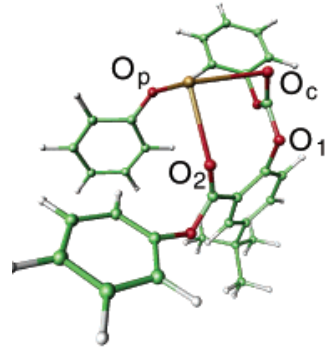

(a)

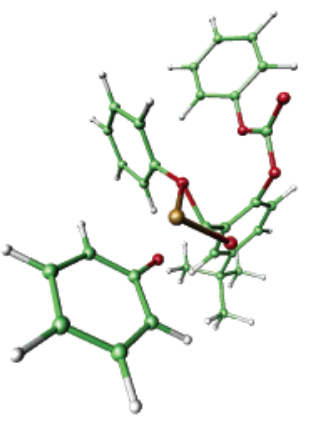

(c)

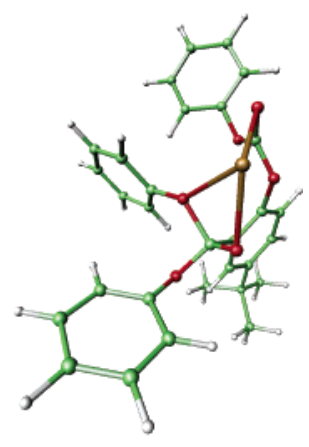

(b)

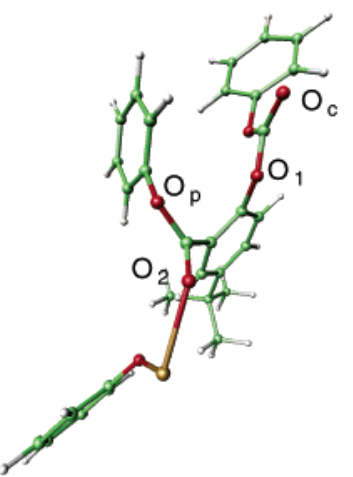

(d)
Figure 3. Second reaction stage. The corresponding energies are denoted $3(\mathrm{a}-\mathrm{d})$ in Figure $4 . \mathrm{O}_{c}$ denotes the carbonyl oxygen of DPC, and $\mathrm{O}_{p}$ is the phenoxyl oxygen.

in an abrupt breaking of one of the initial $\mathrm{Na}-\mathrm{O}$ contacts and an increase in energy to $16.0 \mathrm{kcal} / \mathrm{mol}$.

Changing $\mathrm{T}$ and the $\mathrm{Na}$ displacement (dihedral constraint) in the ester group weakens the $\mathrm{C}-\mathrm{O}$ bond, which is $1.645 \AA$ long for the energy maximum +17.0 $\mathrm{kcal} / \mathrm{mol}$ at $\mathrm{T}=1.5 \AA$. Neither additional displacements of $\mathrm{Na}$ nor reduction of $\mathrm{T}$ broke this bond. Following our experience in reaction 1 , we adopted the reaction coordinate $U$ (see Table 2), which increases the length of the $\mathrm{C}-\mathrm{O}$ bond. We find that small displacements of U (up to $1.8 \AA$ ) lower the total energy and break the 


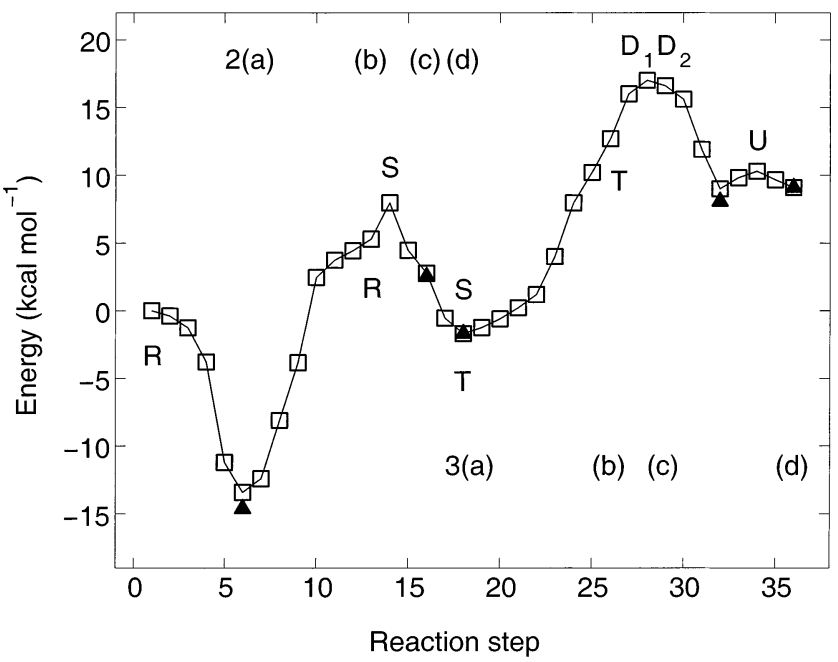

Figure 4. Change in total energy during reactions (see Table 2). Squares show the energies for the reaction coordinates $R$, $\mathrm{S}, \mathrm{T}, \mathrm{D}$, and $\mathrm{U}$; solid triangles show the corresponding values without constraints. The correspondence to the structures in Figures $2 a-d$ and $3 a-d$ is also shown.

$\mathrm{C}-\mathrm{O}$ bond. The phenoxyl $\mathrm{O}$ moves away from the ester group, which gradually adopts a planar configuration, and the ring of the phenoxyl radical moves cl oser to $\mathrm{Na}$. This leads to a stable minimum $(+9.00 \mathrm{kcal} / \mathrm{mol}$ at 3.0 $\AA$ ), which relaxes to $+8.07 \mathrm{kcal} / \mathrm{mol}$ at $3.50 \AA$ ). Here $\mathrm{Na}$ has one $\mathrm{O}$ contact and interactions with the phenoxyl ring, and the substituted phenoxyl O has two low energy hydrogen bonds with aliphatic and aromatic hydrogens of the branched PC ester.

The system goes over a small energy barrier on further increasing $\mathrm{U}$, and the relaxed structure (energy $+9.09 \mathrm{kcal} / \mathrm{mol}$ at $U=4.17 \AA$ ) corresponds to $\mathrm{NaOPh}$ interacting with the branched PC ortho ester. The energy is $11 \mathrm{kcal} / \mathrm{mol}$ higher than in the starting configuration, reflecting the presence of two (i.e., one less) $\mathrm{Na}-\mathrm{O}$ bonds. There is also a contribution from the weak hydrogen bond between NaOPh and the PC ortho ester.

C. Reactions involving $\mathbf{P P h} \mathbf{h}_{\mathbf{4}} \mathbf{O P h}$. The Na-catalyzed PC synthesis induces unfavorable branching side reactions related to the ability of $\mathrm{Na}$ to bind several oxygens simultaneously, so that the active sites are close to each other. We now discuss the possibility of hindering branching reactions by using the tetraphenylphosphonium $\left(\mathrm{PPh}_{4}{ }^{+}\right)$cation. The ionic radius is much larger than in $\mathrm{Na}^{+}$, and four phenyl groups increase the possibility of steric hindrance. An earlier study ${ }^{6}$ showed that the complex of $\mathrm{PPh}_{4}$ with a phenoxyl ion catalyzes exchange reactions in a manner very similar to $\mathrm{NaOPh}$, although the energy barriers are higher.

A parallel study to the reaction with $\mathrm{NaOPh}$ would be excessively demanding of computer resources in the case of $\mathrm{PPh}_{4} \mathrm{OPh}$, but we have performed calculations that shed light on the differences between $\mathrm{PPh}_{4} \mathrm{OPh}$ and $\mathrm{NaOPh}$. First, we have placed the $\mathrm{PPh}_{4}{ }^{+}$cation above the branching initiator (PBNaOB without $\mathrm{Na}^{+}$, Figure $5 b)$ and optimized the geometry. We have then moved the constituents artificially close to each other $(\mathrm{P}-\mathrm{O}$ distance $2.2 \AA$ ) and optimized the resulting structure (Figure 5a). The properties of these two structures and those of $\mathrm{PPh}_{4}^{+}$and $\mathrm{PPh}_{4} \mathrm{OPh}$ are given in Table 3 .

The isomers in Figure 5 differ, in particular, in their $\mathrm{P}-\mathrm{O}$ separations (Figure $5 \mathrm{a}, 2.64 \AA$; Figure $5 \mathrm{~b}, 3.50 \AA$ ). The isomer shown in Figure $5 b$ has more low-energy hydrogen bonds between the aromatic $\mathrm{H}$ atoms of $\mathrm{PPh}_{4}$

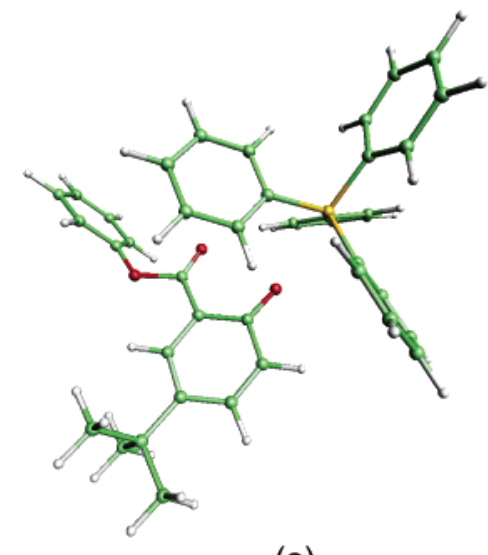

(a)

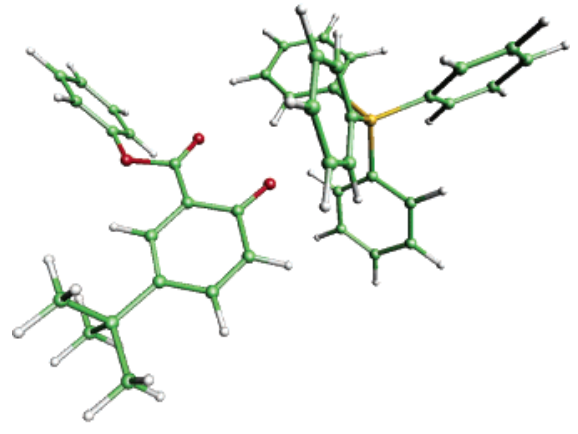

(b)

Figure 5. Structures produced by the reaction of $\mathrm{PPh}_{4}{ }^{+}$with PBNaOB without $\mathrm{Na}^{+}$(Figure 1C). Key: C, green; O, red; $\mathrm{H}$, white; P, yellow.

and the $\mathrm{O}$ atoms, and it is $1.71 \mathrm{kcal} / \mathrm{mol}$ more stable than that in Figure 5a. The ESP charges $\left(0.7\right.$ e in $\mathrm{PPh}_{4}$ in both cases) and the large dipole moment imply a significant el ectrostatic component in the intermol ecular interaction, particularly in Figure $5 \mathrm{~b}$. There is one (weak) $\mathrm{P}-\mathrm{O}$ chemical bond and steric hindrance of the other, a qualitatively different picture from $\mathrm{PBNaOB}$. These calculations indicate that the $\mathrm{PPh}_{4}{ }^{+}$ion cannot approach the branching initiator and will be much less effective than $\mathrm{Na}^{+}$in bringing together the active sites of $\mathrm{PC}$ chains that lead to branching.

\section{Discussion and Concluding Remarks}

Branching of chains in a polymer can lead to large changes in its properties, sometimes beneficial, sometimes less so. The process often involves complicated, multistep reactions whose details can only be inferred from the nature of the product and experience with other reactions. We have studied here a two-step reaction in BPA-PC that provides a possible branching mechanism following the F ries rearrangement of a carbonate group during the melt process of PC manufacture. We focus on the transesterification process and on the role of the catalyst, sodium phenoxide (NaOPh). We have studied the energy surfaces using density functional calculations with a gradient-corrected (PBE) approximation to the exchange-correlation energy and a pseudopotential description of the electron-ion interaction.

The calculations show that the $\mathrm{Na}$ ion in $\mathrm{NaOPh}$ can interact simultaneously with several oxygen atoms, providing both a mechanism for branching and a variety of possible products. Calculations for tetraphenyl phosphonium phenoxide $\left(\mathrm{PPh}_{4} \mathrm{OPh}\right)$ indicate that the active 
Table 3. Properties of Two $\mathrm{PPh}_{4}{ }^{+}$Analogs of $\mathrm{PBNaOB}$ Compared to Tetraphenylphosphonium $\mathrm{Phenoxide} \mathrm{(PPh} \mathrm{OPh}_{4}$ and Tetraphenylphosphonium Cation $\left(\mathrm{PPh}_{4}^{+}\right)^{\mathrm{a}}$

\begin{tabular}{|c|c|c|c|c|}
\hline atoms & Figure $5 a$ & Figure 5b & $\mathrm{PPh}_{4} \mathrm{OPh}^{\mathrm{b}}$ & $\mathrm{PPh}_{4}{ }^{+}$ \\
\hline $\begin{array}{l}\mathrm{P}-\mathrm{O}_{1 \mathrm{~d}} \\
\mathrm{P}-\mathrm{O}_{2 \mathrm{~d}} \\
\mathrm{O}_{1 \mathrm{~d}}-\mathrm{H}_{1 \mathrm{i}} \\
\mathrm{O}_{2 \mathrm{~d}}-\mathrm{H}_{1 \mathrm{i}} \\
\mathrm{O}_{1 \mathrm{~d}}-\mathrm{H}_{2 \mathrm{i}} \\
\mathrm{O}_{2 \mathrm{~d}}-\mathrm{H}_{3 \mathrm{i}} \\
\mathrm{P}-\mathrm{C}_{\mathrm{i}}\end{array}$ & $\begin{array}{l}2.84 \\
4.45 \\
2.36 \\
2.09 \\
\\
1.81,1.85\end{array}$ & $\begin{array}{l}3.50 \\
5.31 \\
2.03 \\
2.43 \\
2.47 \\
2.48 \\
1.81,1.82\end{array}$ & $1.86,1.90$ & 1.81 \\
\hline $\begin{array}{l}\mathrm{P}-\mathrm{O}_{1 d}-\mathrm{C}_{d} \\
\mathrm{C}_{\mathrm{i}}-\mathrm{P}-\mathrm{O}_{1 d^{c}} \\
\mathrm{C}_{\mathrm{i}}-\mathrm{P}-\mathrm{C}_{\mathrm{i}}\end{array}$ & $\begin{array}{l}138.9 \\
176.2 \\
103.2-114.5\end{array}$ & $\begin{array}{l}157.8 \\
166.8 \\
106.0-112.5\end{array}$ & $\begin{array}{l}170.5 \\
99.6-123.9\end{array}$ & $107.5-110.6$ \\
\hline $\begin{array}{l}\mathrm{Q}(\mathrm{P}) \\
\mathrm{Q}\left(\mathrm{C}_{\mathrm{i}}\right) \\
\mathrm{Q}\left(\mathrm{O}_{1 \mathrm{~d}}\right) \\
\mathrm{Q}\left(\mathrm{O}_{2 \mathrm{~d}}\right) \\
\mathrm{Q}\left(\mathrm{PPh}_{4}\right)\end{array}$ & $\begin{array}{l}-0.08 \\
0.06,0.22-0.40 \\
-0.60 \\
-0.52 \\
0.69\end{array}$ & $\begin{array}{l}-0.33 \\
0.22-0.34 \\
-0.48 \\
-0.49 \\
0.70\end{array}$ & $\begin{array}{l}-0.33 \\
0.16,0.32-0.48 \\
-0.62\end{array}$ & $\begin{array}{l}-0.21 \\
0.20,0.30 \\
1.0\end{array}$ \\
\hline dipole & 9.9 & 14.8 & 8.5 & 0.2 \\
\hline
\end{tabular}

a Subscripts $\mathrm{d}$ and i refer to the branching initiator and $\mathrm{PPh}_{4}{ }^{+}$, respectively. Bond distances are in angstroms, and bond angles are in degrees. ${ }^{b}$ From ref 6 . ${ }^{c}$ With respect to the peripheral phenyl group.

site is prevented from approaching the $\mathrm{O}$ atoms, and branching reactions should not take place. We expect that lithium phenoxide should show similar behavior to $\mathrm{NaOPh}$, in line with our experience with the reactions of both with the cyclic tetramer of BPA-PC. The Li ion is somewhat smaller than $\mathrm{Na}$, and there are differences in detail, but the energy barrier and overall picture are similar. ${ }^{5}$

Earlier work in this series has shown that DF calculations can provide insight into the course of complex reactions involving many atoms. Applications have included ring-opening polymerization of BPA-PC cyclic oligomers, exchange reactions involving diphenyl carbonate with $\mathrm{NaOPh}$ and $\mathrm{PPh}_{4} \mathrm{OPh}$, and the role of epoxide and phosphite additives in BPA-PC. The present work provides further evidence of the value of such cal culations. These cal culations are free of adjustable parameters, but we emphasize that they are extremely demanding of computing resources, both in CPU time and in memory. Nevertheless, we are confident that improvements in numerical algorithms and computer hardware will allow future applications in a wide range of contexts.

Acknowledgment. The calculations were performed on Cray T3E computers in the Forschungszentrum J ülich using grants of CPU time provided by the Forschungszentrum and the J ohn von Neumann Institut für Computing. The work was supported by the Bundesministerium für Bildung and Forschung, Bonn, Germany (Kompetenzzentrum Werkstoffmodellierung, 03N6015), and by Bayer AG (Leverkusen, Germany). We thank P. Ballone for hel pful comments and criticism and F. Bruder, S. Kratschmer, and M. Möthrath (Bayer AG, Krefeld, Germany) for suggesting these cal culations and for helpful discussions. J.A. thanks the Academy of Finland and the Väisälä Foundation, Helsinki, for financial support.

\section{References and Notes}

(1) Strobl, G. R. The Physics of Polymers: Concepts for Understanding their Structures and Behavior; Springer, Berlin, 1996.

(2) See, for example: Gels Handbook; Osada, Y., Kajiwara, K., Fushimi, T., Hirasa, O., Hirokawa, Y., Matsunaga, T., Shimomura, T., Wang, L., Eds.; Academic: San Diego, CA, 2000

(3) Oba, K.; I shida, Y.; I to, Y.; Ohtani, H.; Tsuge, S. Macromolecules 2000, 33, 8173.

(4) Brunelle, D. J. In Ring-Opening Polymerization: Mechanisms, Catalysis, Structure, Utility; Brunelle, D. J ., Ed.; Hanser: München, Germany, 1993; 309.

(5) Ballone, P.; Montanari, B.; J ones, R. O. J . Phys. Chem. A 2000, 104, 2793.

(6) Ballone, P.; J ones, R. O. J . Phys. Chem. A2001, 105, 3008.

(7) Kim, S. P.; Lee, J-S.; Kim, S.-H.; Lee, B.-H.; Kim, S. H.; Kim, W-G. J . Ind. Eng. Chem. (Seoul) 1999, 5, 268.

(8) Marks, V.; Hedges, C. V. U.S. Patent 4,469,861, 1984. U.S. patents can be viewed on the Internet at the URL: http:// www.uspto.gov/.

(9) Krabbenhoft, H. O.; Boden, E. P. Makromol. Chem., Macromol. Symp. 1991, 42/ 43, 167.

(10) Mestanza, R.; McCloskey, P.j .; Hoeks, T. L.; Kusters, A. A.; Wu, P.-P.: Lin, Y.-G. U.S. Patent 5,948,876, 1999.

(11) Akola, J .; Ballone, P.; J ones, R. O. Macromol ecules 2002, 35, 2327.

(12) Ballone, P.; J ones, R. O. J . Chem. Phys. 2001, 115, 3895

(13) Ballone, P.; J ones, R. O. J . Chem. Phys. 2002, 116, 7724.

(14) Ballone, P.; J ones, R. O. J . Chem. Phys. 2002, 117, 6841.

(15) I gnatov, V.; Tartari, V.; Carraro, C.; Pippa, R.; Nadali, G.; Berti, C.; Fiorini, M. Macromol. Chem. Phys. 2001, 202, 1941.

(16) I gnatov, V.; Tartari, V.; Carraro, C.; Pippa, R.; Nadali, G.; Berti, C.; Fiorini, M. Macromol . Chem. Phys. 2001, 202, 1946.

(17) Evans, T. L.; Berman, C. B. U.S. Patent 4,701,519, 1987.

(18) Konig, A.; Prein, M. U.S. Patent 6,291,630, 2001.

(19) Kuze, S.; Tanaka, K.; Suga, K.; Seino, Y.; Shishikura, A.; Kunishi, N.; U.S. Patent 5,922,826, 1999.

(20) Kuze, S.; Tanaka, K.; Yabe, A.; I shikawa, M.; Seino, N. U.S. Patent 6,316,575, 2001.

(21) Montanari, B.; J ones, R. O. Chem. Phys. Lett.1997, 272, 347

(22) Troullier, N.; Martins, J. M. Phys. Rev. B 1991, 43, 1993.

(23) Perdew, J . P.; Burke, K.; Ernzerhof, M. Phys. Rev. Lett. 1996, $77,3865$.

(24) Hutter, J. et al. CPMD program version 3.4; Max-PlanckInstitut für Festkörperforschung, Stuttgart, Germany, and IBM Research 1990-2001.

MA021630] 